\title{
Chen, Eom, Mao, and O'Hayre to Chair 2011 MRS Spring Meeting
}

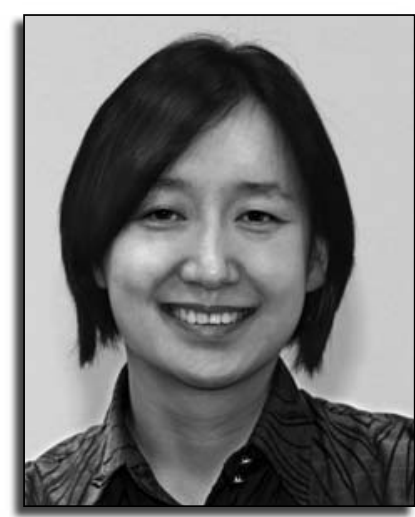

Ping Chen

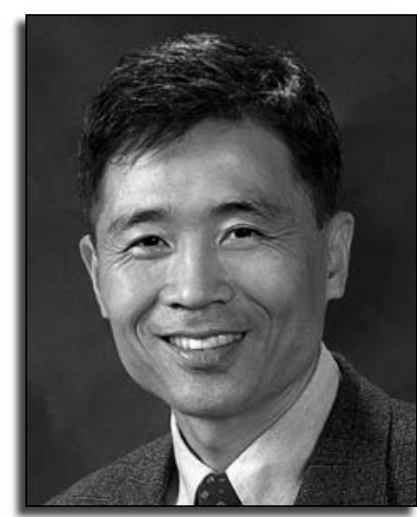

Chang-Beom Eom

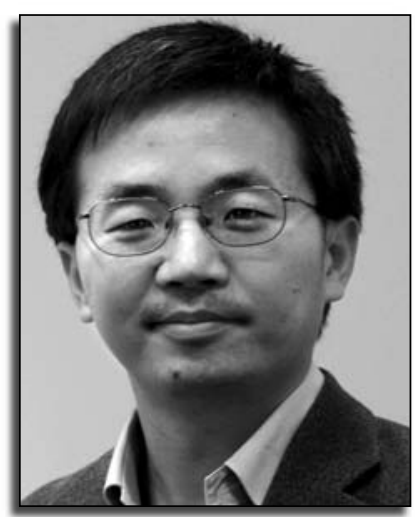

Samuel S. Mao

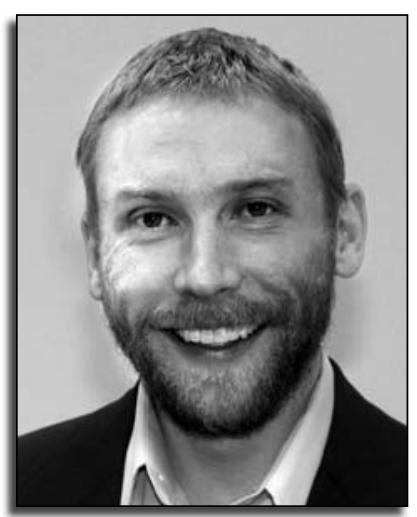

Ryan O'Hayre
Meeting Chairs for the 2011 Materials Research Society (MRS) Spring Meeting are Ping Chen (Dalian Institute of Chemical Physics, China), Chang-Beom Eom (University of Wisconsin-Madison), Samuel S. Mao (Lawrence Berkeley National Laboratory), and Ryan O'Hayre (Colorado School of Mines). The meeting will be held in San Francisco on April 25-29.

Ping Chen is a professor at the Dalian Institute of Chemical Physics, Chinese Academy of Sciences (DICP, CAS). Her primary research interest is the development of hydrides including amides and amidoboranes for hydrogen storage, catalysis, and organic synthesis. She has published over 60 peer-reviewed journal articles since 1999 with 3000 citations and seven patents. Chen received a BS degree in 1991 and a PhD degree in 1997 in chemistry from Xiamen University, China, and was a faculty member in the Physics Department at the National University of Singapore (NUS) before she joined DICP. She received the Temasek Young Investigator award in 2006, NUS University Award in 2007, and the Institute of Physics Singapore award in 2008. In 2009, she was recognized by the Hundred Talent Project, the highest honor of the Chinese Academy of Sciences for young researchers.

Chang-Beom Eom is a professor in the Department of Materials Science and Engineering at the University of WisconsinMadison. His research interests include heteroepitaxy of complex oxide thin film heterostructures, and nanostructure fabrications of novel materials including ferroelectrics, piezoelectrics, multiferroics, superconductors, two-dimensional electron gas systems at the oxide hetero-interfaces. He received his $\mathrm{PhD}$ degree in Materials Science and Engineering from Stanford University in 1991. He has over 200 articles published in peer-reviewed publications with $~ 8000$ citations and a book chapter. Eom's honors include the Ho-Am Prize in Engineering in 2007, the David and Lucile Packard Fellowship (1995), and the National Science Foundation Young Investigator Award (1994). He is a Fellow of the American Physical Society.

Samuel S. Mao is a career staff scientist of Lawrence Berkeley National Laboratory, who is leading a multidisciplinary research team studying laser-material interactions and developing scalable materials synthesis and processing technologies, in particular for clean energy and environmental applications. He joined Lawrence Berkeley National Laboratory as a scientist right after he obtained his PhD degree from the University of California at Berkeley in 2000. He has published over 70 peerreviewed articles and contributed five book chapters, and he holds 12 U.S. and international patents. He has delivered more than 40 invited talks at international conferences, and since 2005 he has served as a judge for the annual "R\&D 100" Technology Awards. He coorganized the first International Energy Nanotechnology Conference and the first International Symposium on Transparent Conducting Oxides.

Ryan O'Hayre is an associate professor of Metallurgical and Materials Engineering at the Colorado School of Mines. His research interests cover several aspects of both fuel cell and solar cell technology. O'Hayre received his $\mathrm{PhD}$ degree in materials science at Stanford University, where he served several additional years as an acting assistant professor in the Department of Mechanical Engineering. O'Hayre developed and taught Stanford's first course on fuel cell science and technology and co-authored a textbook on the same subject. In 2005, O'Hayre held an NSF international postdoctoral fellowship at the Technical University of Delft, the Netherlands, where he researched three-dimensional nanostructured inorganic solar cells. He holds several patents related to fuel cell technology and has authored or coauthored several dozen peer-reviewed articles in the fuel cell and solar cell fields. He has received several younginvestigator research awards, and in 2009 received the Presidential Early Career Award in Science and Engineering, the country's top honor for early-career scientists and engineers.

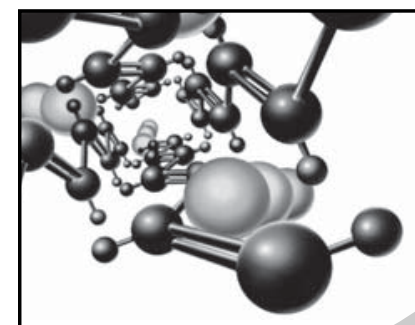

\section{Organic Microelectronics and Optoelectronics Workshop VI July 6-9, 2010, San Francisco Marriott, San Francisco, CA}

For information on this Workshop, including speakers, schedules, lodging and registration visit www.mrs.org/org_micro6 